\title{
OPTIMASI FORMULASI SEDIAAN HANDBODY LOTION EKSTRAK DAUN TEH HIJAU (Camellia sinensis Linn)
}

\author{
S Slamet ${ }^{1}$, Waznah $\mathrm{U}^{2}$ \\ slamet93ffua@gmail.com \\ urmatul.farmasi@gmail.com \\ ${ }^{1,2}$ Stikes Muhammadiyah Pekajangan Pekalongan \\ Jl. Raya Ambokembang no 8 Kedungwuni Kab. Pekalongan
}

ARTICLE INFO :

$\begin{array}{ll}\text { Accepted } & \text { : } \\ \text { Approve } & \text { : }\end{array}$

\begin{abstract}
Introduction: The outer part of the human body is the skin. This skin has an important function to prevent dehydration, prevent the transition / free radicals, maintain body temperature and as a medium to control stimulation (Wasiaatmadja, 1997). The skin also needs treatment so that free radicals are not known from natural ingredients. The aim of this experiment is optimizing the preparation of hand body lotion from tea leaf extract. Some compositions were chosen which were previously oriented to get good preparation consistency. Method: The method used by mixing part A which consists of cetil alcohol, lanolin, stearic acid heated to $70^{\circ} \mathrm{c}$, and part $B$ consists of glycerol, triethanolamine, paraben metal and aquadest which were also heated at the same temperature, then stirred until homogeneous and tea leaf extract was added. Then, the hand body lotion produced was tested. Result :The test results of hand body lotion showed a stable preparation from testing for 3 weeks with a semi-solid form, green colour, aroma of tea, and homogenity, $\mathrm{pH}$ of preparation 7 , dispersion test : $2.8 \times 3.1 \mathrm{~cm} 2-7 \times 8 \mathrm{~cm} 2$, adhesion test : 0.73 seconds - 02.3 seconds. The result of irritation test showed that the hand body lotion is safe or non-irritating in 10 respondents. The conclusion of this experiment is the hand body lotion produced is safe according to the requirements.
\end{abstract}

Keywords: Hand body lotion, green tea leaf extract, maceration, skin.

\begin{abstract}
Abstrak
Pendahuluan: Bagian terluar dari tubuh manusia adalah kulit. Kulit ini yang mempunyai fungsi vital diantaranya berfungsi untuk mencegah dehidrasi, menghambat penetrasi senyawa asing/radikal bebas, mempertahankan suhu tubuh dan sebagai media terjadinya rangsangan (Wasiaatmadja, 1997). Kulit juga memerlukan perawatan agar tidak terkenal radikal bebas terutama dari bahan alami. Tujuan : tujuan riset ini adalah mengoptimasi sediaan hand body lotion dari ekstrak daun teh. Dipilih beberapa komposisi yang sebelumnya dilakukan orientasi untuk mendapatkan kosistensi sediaan yang baik. Metode : Metode yang digunakan adalah dengan mencampurkan bagian A yang terdiri cetil alkohol, lanolin, asam stearat dipanaskan sampai $70^{\circ} \mathrm{c}$, dan bagian $\mathrm{B}$ terdiri gliserol, trietanolamin, metal paraben dan aquadest yang juga dipanaskan pada suhu yang sama, kemudian diaduk sampai homogen dan ditambahkan ekstrak daun teh. Kemudian hand body lotion yang dihasilkan dilakukan uji. Hasil : Hasil uji sediaan
\end{abstract}


hand body lotion menunjukkan sediaan yang stabil dari pengujian selama 3 minggu dengan bentuk setengah padat, warna hijua, aroma teh, dan homogen, $\mathrm{pH}$ sediaan 7 , uji daya sebar : 2,8 $\mathrm{x} 3,1 \mathrm{~cm}^{2}-7 \mathrm{x} 8 \mathrm{~cm}^{2}$, uji daya lekat 0.73 detik - 02.3 detik. Hasil dari Uji iritasi menunjukkan bahwa hand body lotion aman atau tidak menimbulkan iritasi pada 10 responden. Kesimpulan dari penelitian ini adalah hand body lotion yang dihasilkan aman sesuai dengan persyaratan.

Kata Kunci : Hand body lotion, Ekstrak daun teh hijau, maserasi, kulit.

\section{PENDAHULUAN}

Kulit adalah bagian terluar dari tubuh manusia. Kulit ini yang mempunyai fungsi vital diantaranya berfungsi untuk mencegah dehidrasi, menghambat penetrasi senyawa asing/radikal bebas, mempertahankan suhu tubuh dan sebagai media terjadinya rangsangan (Wasiaatmadja, 1997). Teh hijau mengandung senyawa polifenol yang bermanfaat sebagai antioksidan yang dapat menunda, memperlambat, dan mencegah proses oksidasi lipida. Senyawa antioksidan alami umumnya adalah senyawa fenolik atau polifenolik yang merupakan golongan flavonoid (Suyoso, 2011). Kandungan polifenol dalam teh hijau antara lain flavanol, flavonoid dan asam fenolik (hingga $30 \%$ dari berat kering). Untuk mempermudah penggunaan antioksidan dalam penelitian ini dibuat dalam bentuk sediaan handbody lotion.

Handbody lotion adalah sediaan kosmetik yang diaplikasikan pada kulit dari bagian tangan dan tubuh. Lotion dapat berbentuk suspensi zat padat dengan bahan pensuspensi yang cocok, atau emulsi tipe minyak dalam air dengan surfaktan yang sesuai (Mitsui, 1997). Menurut Depkes (1979) lotion adalah sediaan cair berupa suspensi atau dispersi. Dapat berbentuk suspensi zat padat dalam bentuk serbuk halus dengan bahan pensuspensi yang cocok atau emulsi tipe minyak dalam air dengan surfaktan yang cocok. Pemilihan sediaan lotion karena merupakan sediaan yang berbentuk emulsi ang mudah dicuci dengan air dan tidak lengket di bandingkan sediaan topikal lainnya. Selain itu bentuknya yang cair memungkinkan pemakaian yang cepat dan merata pada kulit._Tujuan penelitian ini adalah membuat formula handbody lotion yang mengandung antioksida dari ekstrak daun teh dengan formulasi bahan yang menggunakan cetil alkohol, lanolin, asam stearat, gliserol, trietanolamin, metal paraben dan aquadest. Serta melakukan uji evaluasi sediaan handbody lotion seperti pengujian organoleptis, $\mathrm{pH}$, daya sebar, daya lekat dan pengujian iritasi. 
METODE

Bahan penelitian ekstrak daun teh hijau (Camellia sinensis Linn.) yang didapat dari tanaman dengan metode maserasi dengan pelarut etanol, setil alkohol, lanolin,gliserol, trietanolamin, metal paraben dan aquadest

Alat penelitian ekstrak daun teh hijau (Camellia sinensis Linn.) yaitu mortir, stamper, sudip, penangas air, cawan porselin, pengaduk, alat gelas, evaporator heidolph, blender, ayakan mesh 40, pH meter.

\section{Formulasi Sediaan Handbody Lotion}

Pembuatan Sediaan Handybody Lotion Ekstrak Daun teh hijau menggunakan bahan bahan sebagai berikut : Bagian A: Cetil alcohol, Lanolin, Asam stearat. Bagian B : Gliserol , Trietanol amin, Metil paraben, Ekstrak teh, Aquades ad

\section{Pembuatan Handybody Lotion Ekstrak Daun Teh Hijau}

Bagian A (setil alkohol, lanolin, asam stearat) dipanaskan sampai $70^{\circ} \mathrm{c}$, begitu pula bagian B (gliserol, trietanolamin, metal paraben dan aquadest). Bagian B ditambahkan kedalam bagian A sedikit demi sedikit sampai diaduk sampai homogen.
Campurkan perlahan-lahan didinginkan sampai terus menerus diaduk sampai suhu $40^{\circ} \mathrm{C}$ sehingga menjadi lotion. Campuran ditambahkan ekstrak daun the hijau, aduk sampai homogen.

\section{Evaluasi Sediaan Handybody Lotion Ekstrak Daun Teh Hijau.}

\section{Organoleptis}

Uji organoleptis dilakukan melihat bentuk, bau warna dan homogenitas sediaan. Dilakukan dengan indra (diuji selama 3 minggu)

\section{PH}

Sediaan diuji dengan menggoreskan pada $\mathrm{pH}$ stick ( $\mathrm{pH}$ universal). Dilihat $\mathrm{pH}$ sediaan dari perubahan warna stick.

\section{Pengujian Daya Sebar}

Sediaan gel ditimbang sebanyak 0,5 gram dan diletakkan di atas kaca yang pada bagian sisi lainnya telah ditempeli millimeter blok. Di atas kaca ditambahkan pemberat 50 gram sampai 250 gram. Pada setiap penambahan ditunggu 1 menit dan dilihat diameter dari handbody lotion.

\section{Pengujian Daya Lekat}

Pengujian daya lekat dilakukan dengan melihat zat aktif terikat kuat pada basis, dan 
dapat dilepaskan saat basis melepaskan air dan mengering

\section{Uji Iritasi}

Uji iritasi dilakukan dengan mengaplikasikan handybody pada punggung tanggan 10 responden yang berbeda selama minimal 15 menit dilihat reaksi yang ditimbulkan

\section{HASIL DAN PEMBAHASAN}

Handbody lotion merupakan sediaan kosmetik yang digunakan untuk melindungi kulit supaya tetap halus dan lembut tidak kering, tidak bersisik dan tidak mudah pecah biasanya handbody lotion dibuat dalam bentuk cream atau cream cair (lotion) dan emulsi ( Depkes RI 1995), sediaan hand body yang dibuat termasuk dalam bentuk cream minyak dalam air (o/w) sehingga aplikasi ini saat diaplikasikan dalam kulit tidak terasa lengket. Dalam hal ini sediaan ini mengandung ekstrak daun teh yang berguna sebagai antioksidan.

Dalam penelitian ini pembuatan ekstrak daun teh menggunakan metode maserasi dimana metode ini merupakan metode tanpa pemanasan/dingin sehingga dapat mencegah kerusakan komponen kimia yang tidak tahan terhadap pemanasan (syukur,at.,al 2011) sehingga cocok untuk mengekstrak zat aktif .kemudian dilakukan pemekatan dengan menggunakan rotary evaporator dengan bantuan alat pompa vakum. Proses bertujuan untuk memekatkan larutan yang terdiri dari zat yang terlarut maupun zat yang tidak terlarut. Menurut toyamahu (2014) bantuan pompa vakum akan menentukan tekanan uap pelarut sehingga pelarut akan menguap di bawah didih normalnya. Tujuanya adalah agar komponen fitokimia yang terdapat dalam ekstrak tidak mengalami kerusakan yang lebih.

\section{A. Uji Daya Sebar}

Dibawah ini hasil uji daya sebarhandbody lotion dengan 3 formula yang berbeda.

Tabel 1. Uji Daya Sebar Handbody lotion dari 3 formula

\begin{tabular}{|c|c|c|c|c|c|c|c|c|c|}
\hline \multirow{3}{*}{$\begin{array}{l}\text { Fo } \\
\text { rm } \\
\text { ula }\end{array}$} & M0 & \multirow[t]{2}{*}{ M1 } & M2 & & & & & & \\
\hline & $\begin{array}{c}\text { Be } \\
\text { ban } \\
\text { (g) }\end{array}$ & & & & & & & & \\
\hline & 0 & 100 & 200 & 0 & 100 & 200 & 0 & 100 & $\begin{array}{c}20 \\
0\end{array}$ \\
\hline $\mathrm{A}$ & $\begin{array}{c}6 x \\
6\end{array}$ & $\begin{array}{l}6 \mathrm{x} \\
6,5\end{array}$ & $\begin{array}{l}7 \mathrm{x} \\
6,5\end{array}$ & $\begin{array}{c}5 \mathrm{x} \\
5\end{array}$ & $\begin{array}{c}6 \mathrm{x} \\
6\end{array}$ & $\begin{array}{c}6,2 \times \\
6\end{array}$ & $\begin{array}{c}2,6 \times x \\
3\end{array}$ & $\begin{array}{c}3,5 \times \\
3,3\end{array}$ & $\begin{array}{c}4,5 \\
x \\
3,8\end{array}$ \\
\hline B & $\begin{array}{l}6 \times x \\
5,5\end{array}$ & $7 \times 7$ & $7 \times 8$ & $\begin{array}{l}5,7 \\
\times 5\end{array}$ & $\begin{array}{l}6,5 \\
x 6\end{array}$ & $\begin{array}{c}6,7 \times 6 \\
5\end{array}$ & $\begin{array}{c}2,8 \times 3, \\
1\end{array}$ & $4 \times 3,5$ & $\begin{array}{c}5 \mathrm{x} \\
4\end{array}$ \\
\hline $\mathrm{C}$ & $\begin{array}{c}6 x \\
7\end{array}$ & $\begin{array}{c}7,5 \mathrm{x} \\
7\end{array}$ & $8 \times 8$ & $\begin{array}{c}6 x \\
6\end{array}$ & $\begin{array}{c}6,5 \\
\times 6, \\
5\end{array}$ & $7 \times 7$ & $\begin{array}{c}3,3 \times 3 \\
5\end{array}$ & $\begin{array}{c}3,7 \times 3, \\
6\end{array}$ & $\begin{array}{l}3,9 \\
\mathrm{x} 4\end{array}$ \\
\hline
\end{tabular}

Pengujian daya sebar dari semua sediaan hand body lotion bertujuan untuk mengetahui apakah daya sebar ke 3 sediaan itu baik atau tidak dan jika daya sebarnya 
semakin besar maka pelepasan efek terapi yang di inginkan di kulit akan semakin cepat (rahman, 2008) dari data di atas dapat dilihat bahwa pada minggu ke-0 memiliki daya sebar yang paling tinggi dan pada minggu.

terakhir penujian memiliki daya sebar yang terendah. Dari ke 3 sediaan dapat dilihat perbandingan komposisi antara cetilalkohol ,lanolin. Cetilalkohol semakin banyak komposisinya akan menyebabkan sediaan handbody semakin pekat(kental) dan bila makin banyak lanolin akan menyebabkan sediaan akan cair.

\section{B. Uji Organoleptis}

Tabel 3. Hasil Uji Organoleptis dari 3 formulas

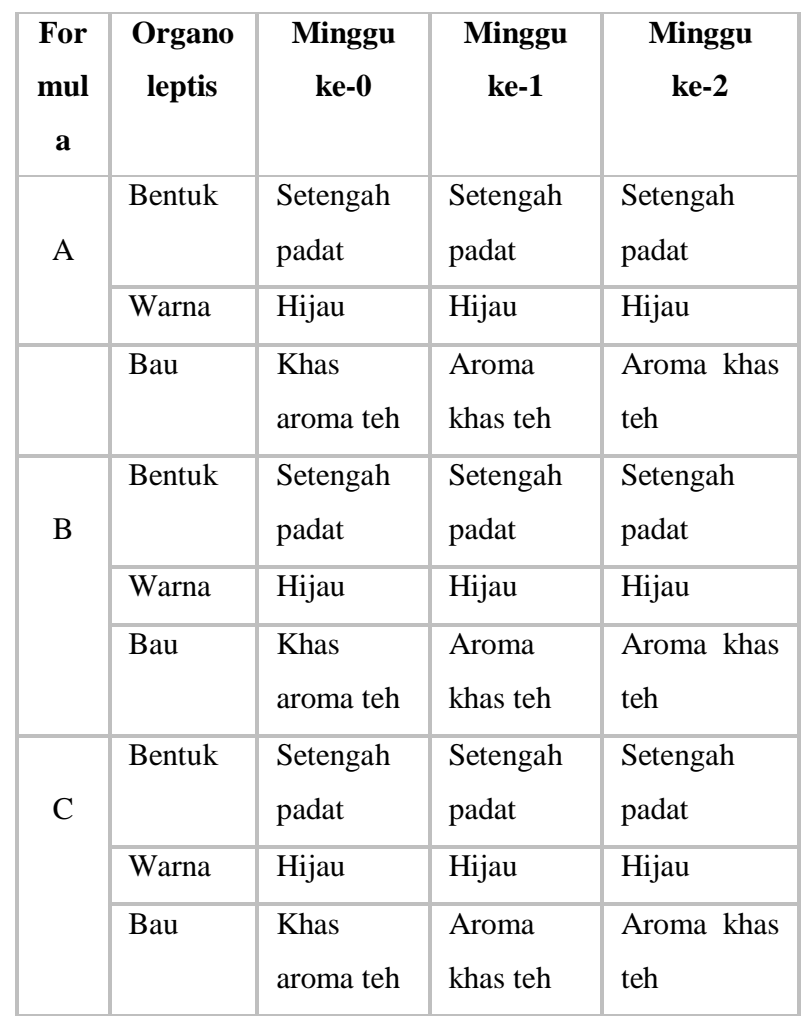

Dari data di atas bahwa organoleptis sediaan dari bentuk, warna dan bau tidak megalami perubahan dari awal pembuatan sampai akhir pembuatan. Dalam hal ini sesuai dengan literatur.

\section{Uji Iritasi}

Uji iritasi ini penting dilakukan untuk mengetahui tingkat kemampuan ke 3 handbody lotion untuk mengiritasi kulit sekaligus mengetahui tingkat keamanan produk lotion yang dibuat ( $\mathrm{Lu}, 1995)$ dalam sediaan baik dari pengujian minggu ke-0 sampai minggu ke-1 dari ke 2 handbody lotion tidak ada yang menyebabkan iritasi pada kulit.

\section{Uji PH}

Tabel 4. Hasil Uji pH sediaan Handbody Lotion

\begin{tabular}{|c|c|c|c|}
\hline \multirow{2}{*}{$\begin{array}{c}\text { Form } \\
\text { ula }\end{array}$} & \multicolumn{3}{|c|}{$\mathrm{pH}$} \\
\cline { 2 - 4 } & M0 & M1 & M2 \\
\hline A & 7,2 & 7,2 & 7,3 \\
B & 7,0 & 7,0 & 7,1 \\
C & 7,0 & 7,1 & 7,1 \\
\hline
\end{tabular}

Dari pengujian ini $\mathrm{pH}$ yang dihasilkan dari minggu ke-0,1 dari ke 2 formula masih dalam range persyaratan literatur menurut SNI 16,4339-1996 pH dalam lotion antara 4,5-8 sehingga sediaan lotion aman untuk kulit. 


\section{E. Uji Homogenitas}

Pada minggu ke-0 sediaa ke 3 nya adalah homogen kemudian pada minggu ke-1 hasilnya sediaanya kurang homogen dan apabila di kocok homogen kembali kemudiaan pada minggu ke-2 sediaanya kurang homogen dan apabila di kocok homogen kembali. Dalam hal ini uji homogenitas bertujuan untuk melihat dan mengetahui tercampurnya sediaan hand body lotion.

\section{F. Uji Daya Lekat}

Tabel 5. Hasil Uji Daya Lekat Sediaan Handbody

\begin{tabular}{|c|c|c|c|c|}
\hline Formula & Replikasi & M0 & M1 & M2 \\
\hline \multirow{3}{*}{ A } & 1 & 01,5 & 02,25 & 02,3 \\
\cline { 2 - 5 } & 2 & 01,6 & 02,30 & 02,4 \\
\hline \multirow{3}{*}{ B } & 3 & 01,7 & 02,02 & 02,4 \\
\cline { 2 - 5 } & 2 & 01.4 & 01.98 & 01.39 \\
\cline { 2 - 5 } & 3 & 01.5 & 02.1 & 01.51 \\
\hline \multirow{3}{*}{ C } & 1 & 01,4 & 02.3 & 0.73 \\
\cline { 2 - 5 } & 2 & 01,9 & 02,01 & 0,90 \\
\cline { 2 - 5 } & 3 & 02,7 & 02,12 & 02,11 \\
\hline
\end{tabular}

Uji daya lekat itu penting berguna untuk mengevaluasi sejauh mana sediaan lotion dapat menempel pada kulit sehingga efek terapi yang diharapkan dapat tercapai bila memiliki daya lekat yang kuat akan menghambat pernafasan kulit dan apabila daya lekat yang terlalu lemah akan mempengaruhi efek terapi (Voight,1995) dalam hal ini daya lekat salep kurang baik karena kurang dari waktu syarat daya lekat yang baik, dimana daya lekat salep yang baik menurut literatur yaitu lebih dari 4 detik ( Nevi , 2006 )

\section{SIMPULAN}

Berdasrkan penelitian yang telah dilakukan maka dapat diambil kesimpulan bahwa ekstrak daun teh dapat diformulasikan sebagai sediaan lotion yang stabil secara fisik berdasrkan parameter $\mathrm{PH}$, bau, warna dan bentuk. Serta daya sebar dan daya lekat.

Dalam hal ini sediaan hand body tidak megiritasi kulit responden. Sediaan hand body yang dibuat memiliki fungsi atau khasiat sebagai antioksidan.

\section{DAFTAR PUSTAKA}

Departemen kesehatan RI. 1995.

Farmakope Indonesia Edisi IV jakarta: Depkes RI.

Lu,F.C., 1995. Toksikologi dasar,asas, organ sasaran, dan peneliaan resiko (terjemahan) Nugroho Edisi ke-2 .jakarta Ui-press.

Rahman,AG, 2008 Formulasi Lotio Ekstrak Rimpang Bengle dengan Variasi kosentrasi Trietinolamin Sebagai Elmugator dan Uji Iritasinya ,Skripsi ,Purwokerto: Fakultas Farmasi Universitas Muhammadiyah 
Purwokerto.

SNI. 16.4399. 1996. Sediaan Tabir Surya. Jakarta : Dewan Standarisasi Nasional

Syukur ,R,. Alam,G ., Mufidah.,Rahim A.,Tayeb R.2011.Aktivitas Antiradikal Bebas Beberapa Ekstrak Tanaman Fabaceae. JTS Kesehatan Vol.1 No1:61-67.ISSN 1411-467

Tomayahu, R. 2014. Identifikasi Senyawa Aktif dan Uji Toksisitas Ekstrak Daun Binahong
(Andrederacordifolia Ten. Steenis) dengan Metode Brine 86Shrimp Lethality Test (BSLT) [Tesis]. Gorontalo: Universitas Negeri Gorontalo

Voight., R., 1995. Buku Pelajaran Teknologi farmasi Yogyakarta:Gadja mada university Press 